\title{
Study on the Composition and Super Critical Carbon Dioxide Extraction of Chinese Hickory (Carya cathayensis Sarg.) Kernel Oil
}

\author{
Lisong Hu, Menghao Du, Shaohai Guo \\ Research Institute of Subtropical Forestry, Chinese Academy of Forestry, Fuyang, China \\ Email: lisohu@hotmail.com
}

How to cite this paper: Hu, L.S., Du, M.H. and Guo, S.H. (2019) Study on the Composition and Super Critical Carbon Dioxide Extraction of Chinese Hickory (Carya cathayensis Sarg.) Kernel Oil. American Journal of Analytical Chemistry, 10, 579-589. https://doi.org/10.4236/ajac.2019.1011040

Received: September 10, 2019

Accepted: November 25, 2019

Published: November 28, 2019

Copyright ( 2019 by author(s) and Scientific Research Publishing Inc. This work is licensed under the Creative Commons Attribution International License (CC BY 4.0). http://creativecommons.org/licenses/by/4.0/

\begin{abstract}
Chinese hickory (Carya cathayensis Sarg.) is one of the most productive woody oil-bearing plant in China. Four different extraction methods were explored and supercritical $\mathrm{CO}_{2}$ was selected as green and non-toxic solvent to extract Chinese kernel oil. Four experiment factors, particles size, extraction time, extraction temperature and extraction pressure, were selected to carry out the single factor experiments. According to the results of orthogonal experiments design, the condition of $\mathrm{B}_{3} \mathrm{C}_{2} \mathrm{~A}_{2} \mathrm{D}_{2}$ was the optimum reaction parameters. When the experiments were carried out at the optimum parameters, the yield of Chinese hickory kernel oil was $74.5 \%$. The oil fatty acids profiles were analyzed, the results showed that total unsaturated fatty acids were $93.05 \%$. Among them, oleic acid was $66.5 \pm 0.44$ as the main component. Saturated fatty acids were $6.92 \pm 0.21$.
\end{abstract}

\section{Keywords}

Chinese Hickory, Extraction, Supercritical $\mathrm{CO}_{2}$, Fatty Acids

\section{Introduction}

In recent years, food safety draws a lot of attention. In ordinary daily life, edible oil is usually used to cook almost in every dish. However, some unhealthy cooking styles like fried and high temperature boiling will lead to some hazard chemicals produced, and these substances such as dioxine, polycyclic aromatic hydrocarbons which could raise high risk of cancer. Therefore, to prevent toxic substances forming in manufacturing edible oils is essential in processing period.

The plant-based oils that obtained from fruits seeds and vegetables are usually processing by screw pressing, solvent extraction and cold pressing [1] [2] [3]. 
Screw pressing is a very efficient method with lower contents of oil in cake of residues of raw materials. However, during the whole screw pressing, temperature of screw process is high $\left(100^{\circ} \mathrm{C}-200^{\circ} \mathrm{C}\right)$. And at the high temperature, toxic chemicals will be formed; color of oil will grow darker; flavor of oil will be degraded; nutritional value of oil will be decreased; and taste of oil will grow bad. Cold-pressed applied to process the oils through a combination of grinding and low heat is healthier than conventionally method made oil with screwing press. Solvent extraction is high efficient and needs ambient temperature. However, solvents are difficult to remove all out of the oil. In conventional extraction, raw materials are heated to very high temperatures, sometimes up to $230^{\circ} \mathrm{C}$, which changes their chemical structure.

In recent years, many researchers pay more attention to supercritical fluid extraction technology as an important alternative to the traditional separation methods. Supercritical fluid extraction technology has been growing rapidly in many fields [4] [5] [6], since the before mentioned limitation can be avoided [7]. Compared to traditional method, supercritical fluid extraction technology has advantages: mild critical point (critical temperature $31.7^{\circ} \mathrm{C}$ and critical pressure around $7 \mathrm{MPa}$ ) green, high yields, no residue, non-toxicity, low cost and high selectivity to non-polar molecules [8]. Super critical $\mathrm{CO}_{2}$, a well-known technology used to extract high added value compounds from many different sources, has been the most used supercritical solvent, because the compounds can be obtained without contamination by toxically organic solvents and without thermal degradation [9].

Chinese hickory (Carya cathayensis Sarg.) as a native species in China is one of the most productive woody oil-bearing plant according to the "Compendium of Materia Medica" [10]. Chinese hickory has been used to keep fit and prevent cardiovascular diseases and treat cough, stomach ache, and cancer in Asia and Europe [11]. Chinese hickory kernels contain $60 \%$ to $70 \%$ oil and the oil contains approximately $7 \%$ saturated, $20 \%$ monounsaturated and $73 \%$ polyunsaturated fatty acid; Besides oleic acid, other compositions include a moderate amount of linoleic acid $20 \%$ and low concentrations of palmitic $4 \%$, stearic $2 \%$, and linolenic acid 5\% [12] [13] [14].

In this study, firstly supercritical $\mathrm{CO}_{2}$ as the solvent was applied to extraction kernel oil of China hickory and several extraction parameters such as pressure, temperature and particle size were studied on the extraction yield of kernel oil of Chinese Hickory. Secondly, orthogonal experimental method was adopted to optimize the yields of extraction. Last, the fatty acid profiles of Chinese hickory samples from extraction by supercritical $\mathrm{CO}_{2}$ were determined by GC-MS.

\section{Experimental}

\subsection{Raw Materials and Chemicals}

Kernel of Chinese hickory was purchased from Lin'an Hangzhou City, China and stored in refrigerator at $2^{\circ} \mathrm{C}-4^{\circ} \mathrm{C}$ till treatment. The kernels were dried at $105^{\circ} \mathrm{C}$ for $24 \mathrm{~h}$, to a moisture content of $7 \%-8 \%$ then milled and screened using 
a milling machine (Hebi Metallurgy Machinery Equipment Co., Ltd. Hebi, China) to obtain powder with a diameter under $0.3 \mathrm{~mm}$, before the experiments.

The chemicals and reagents were bought all from aladdin chemical company China.

\subsection{Solvent Extraction}

Oil was extracted from $5 \mathrm{~g}$ of Chinese hickory (dried and milled) using n-hexane. The extractions were carried out in a Soxhlet apparatus with $50 \mathrm{~mL}$ of boiling $\mathrm{n}$-hexane for $8 \mathrm{~h}$. The mixture of oil and hexane was collected, concentrated under vacuum, and dried for $5 \mathrm{~min}$ at $105^{\circ} \mathrm{C}$ [15].

\subsection{Moisture Content}

Moisture content of ground Chinese hickory kernel was determined by air oven standard methods recommended by the AOAC. Brifely $5 \mathrm{~g}$ of sample in triplicate was dried in hot air oven at $130^{\circ} \mathrm{C}-133^{\circ} \mathrm{C}$ for $2 \mathrm{~h}$. After drying, the dried sample was again weighed. The following Equation (1) was used for calculating the moisture content [16].

$$
\begin{aligned}
& \text { Moisture content }(\%) \\
& =\frac{\text { Initial weight of sample }- \text { Weight sample after heat }}{\text { Initial weight of sample }} \times 100 .
\end{aligned}
$$

\subsection{Determination of Yield of Chinese Kernel Oil}

Oil yield was determined per kernel sample (100 g) on a dry weight basis, using the following Equation (2):

$$
\text { Oil yields }(\%)=\frac{\text { Weight of extracted oil }}{\text { Weight of kernels }} \times 100 \text {. }
$$

\subsection{The Fatty Acid Profiles}

The fatty acid composition of Chinese hickory kernel oil was determined by first converting the oil into fatty acid methyl esters [17]. Briefly, mixture of $1 \mathrm{ml}$ of n-hexane and $200 \mathrm{l}$ of $2 \mathrm{M}$ sodium methoxide were added into $40 \mathrm{mg}$ of Chinese hickory kernel oil, then mixed with $200 \mathrm{ml}$ of $2 \mathrm{~N} \mathrm{HCl}$ in water bath at $50^{\circ} \mathrm{C}$ for a while.

GC-MS analysis were performed on a GC-MS HP7890B gas chromatograph equipped with a HP-5973 mass selective detector using a polar capillary column (HP-Innowax polyethylene glycol, $30 \mathrm{~m} \times 0.25 \mathrm{~mm}$ id., $0.25 \mathrm{~m}$ film thickness HP-wax capillary column (5\% Phenyl Methyl Siloxane, Agilent 19091 J-413) with helium as carrier gas. The detector temperature was $240^{\circ} \mathrm{C}$; Column temperature program was 120 for $2 \mathrm{~min}$ and then programmed to $180^{\circ} \mathrm{C}$ for $2 \mathrm{~min}$ at $10^{\circ} \mathrm{C} / \mathrm{min}$, then increased to $280^{\circ} \mathrm{C}$ for $10 \mathrm{~min}$ at $3^{\circ} \mathrm{C} / \mathrm{min}$. Fatty acids compounds were identified by comparing their mass spectra with the mass spectra from MS database (NIST 05, WILEY 7).

\subsection{Supercritical Fluid Extraction Equipment and Procedure}

The supercritical $\mathrm{CO}_{2}$ extraction experiments were carried out in a lab-scale ex- 
traction systems (Applied Separations Inc. PA, USA), whose diagram is shown in Figure 1. The carbon dioxide used was $\mathrm{CO}_{2}$ (purity 99.99\%) and was supplied by Hangzhou gas Co., Ltd. China. The maximum specifications of this experimental setup are $150^{\circ} \mathrm{C}$ and $50 \mathrm{MPa}$. The extractor has a volume of $26.5 \mathrm{~mL}$ with $1 / 2$ " internal diameter. In a typical experiment, around $20 \mathrm{~g}$ of Chinese hockery were placed in the extractor, which was pressurized with $\mathrm{CO}_{2}$ up to the extraction pressure. Then, the solvent flowed at the desired pressure and temperature (at a mass rate of $0.14 \pm 0.02 \mathrm{~kg} / \mathrm{h}$ ) for the desired time (maximum $3 \mathrm{~h}$ ). Different combinations of pressure and temperature were tried in order to study their influence on the extraction performance [18].

\subsection{Orthogonal Experiments Designing and Data Analysis}

After the single factor experiments, the effect of parameters on super critical $\mathrm{CO}_{2}$ extraction was simultaneously studied using a four factor design, with three levels for each factor (see Table 1). The selected factors were particles size of Chinese hickory, extraction temperature, extraction pressure, extraction time and extraction temperature. The orthogonal table $\mathrm{L}_{9}(3)^{4}$ was designed and three levels were set for each factor, and the boundary values for the levels were determined in pilot experiments [19].

Each extraction experiments was analyzed there separate times. Averages of the data and their standard deviations were calculated and presented as error bars. An ANOVA analysis was performed to evaluate statistically the influence of cold pressing and $\mathrm{CO}_{2}$ extraction at different parameters. Values are presented as means \pm standard deviations.

\section{Results and Discussion}

\subsection{Extraction of Chinese Kickory Oil}

Oil extraction method was divided into 2 kinds. One kind is physical method e.g. cold press and screw press. Cold press had drawn a lot of attention due to its application with low temperature and ecofriendly. In comparison with cold process, screw process which leads to high temperature were very effectively and less residue oil in cake. However, screw process is prone to produce hazard chemicals. The other kind is solvent method like acetone, hexane, No. 6 solvents etc. Solvent extraction with soxhlet apparatus could obtain the theoretical yield of plant's fruit, seed and so on. Nevertheless, solvents in oil are extremely removed out thoroughly. As shown in Figure 2, in this paper, four extraction methods applied to extract Chinese hickory oil were accessed according to their oil yields. Among them, hexane extraction was showed high yield $(75 \% \pm 4.3 \%)$ of Chinese kernel oil. Yield $(52 \% \pm 2.5 \%)$ of Chinese oil obtained from cold express method was lower than other methods. Supercritical $\mathrm{CO}_{2}$ extraction was a green, no residues and keeping compositions of Chinese hickory kernel oil fresh. Yield of Chinese hickory kernel oil obtained by Supercritical $\mathrm{CO}_{2}$ extraction could reach $66 \% \pm 3.6 \%$ at the comparison experiments. 


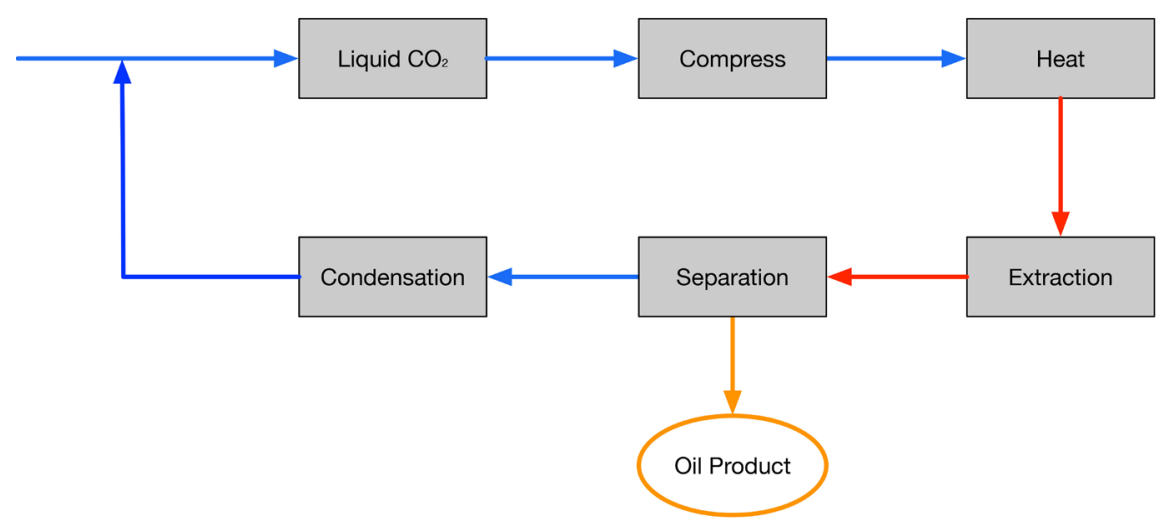

Figure 1. The supercritical $\mathrm{CO}_{2}$ extraction flow chat.

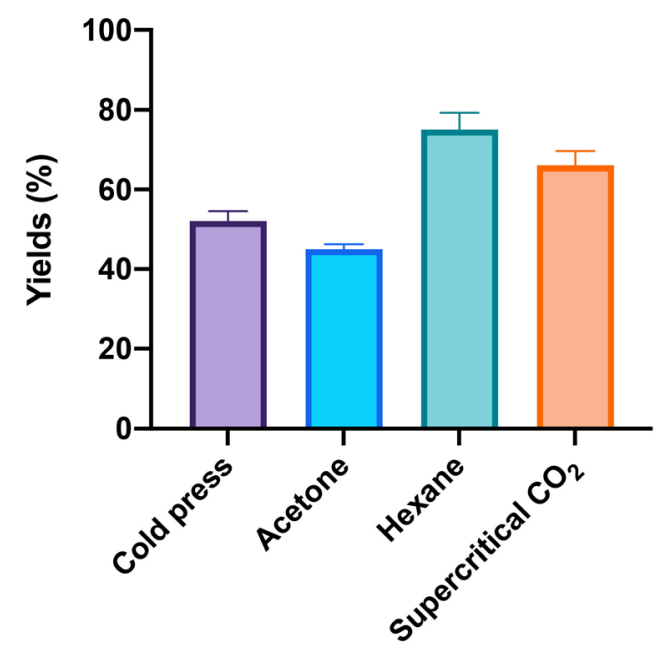

Figure 2. Effects of extraction methods. Data are presented as means, the error bars indicate standard deviations $(n=3)$.

Table 1. Design of orthogonal table $\mathrm{L}_{9}(3)^{4}$ and yields of Chinese hickory kernel oil.

\begin{tabular}{ccccc}
\hline \multirow{5}{*}{ Level } & \multicolumn{4}{c}{ Effective facotrs } \\
\cline { 2 - 5 } & $\begin{array}{c}\text { A: particles size } \\
(\text { mesh })\end{array}$ & $\begin{array}{c}\text { B: extraction time } \\
(\mathrm{h})\end{array}$ & $\begin{array}{c}\text { C: extraction pressure } \\
(\mathrm{Mpa})\end{array}$ & $\begin{array}{c}\text { D: extraction temperature } \\
{ }^{\circ} \mathrm{C}\end{array}$ \\
\hline 1 & 20 & 1.2 & 25 & 35 \\
2 & 30 & 2 & 30 & 40 \\
3 & 40 & 3 & 35 & 45 \\
\hline
\end{tabular}

\subsection{The Effects of Particles Size}

In this paper, super critical $\mathrm{CO}_{2}$ extraction were evaluated by studying reaction factors such as particle size of Chinese hickory kernel, reaction time, reaction pressure and reaction temperature. The moisture in kernel of Chinese hickory was reduced at dry cabinet at $105^{\circ}$ for $8 \mathrm{~h}$ to remove excess moisture. The crashed kernels of Chinese hickory were good for solvents to penetrate into inner kernels of Chinese hickory and curtail diffusion distance between solvent molecules and solid particles. And small particles size were as well as benefit for 
extraction process, theoretically, extraction speed will get more faster, when particles size are smaller. However, when particles of raw materials were too small, the raw materials were prone to be pressed very tightly; and the gas tube of experimental equipment was apt to be blocked. As shown in Figure 3, particles size at 20 to 40 mesh were optimum for experiments.

\subsection{Effects of Extraction Time}

In timeline, supercritical extraction has 3 phases: begin phase, transfer phase and end phase. At the begin phase, particles contacted insufficiently with solvents, in this situation, the solvent was sufficient to particles. So, at begin phase, the extraction speed was very fast as shown in Figure 4. Followed, at transfer phase, more solvents contacted to particles of Chinese hickory kernel oil, therefore, more oil were obtained. The yields of Chinese hickory oil grew rapidly. At the end of phase, supercritical $\mathrm{CO}_{2}$ extraction grew slowly till no oil extracted from Chinese hickory. The optimum time was $2.5 \mathrm{~h}, 3 \mathrm{~h}$ and $3.5 \mathrm{~h}$.

\subsection{Effects of Extraction Pressure}

During the process of supercritical $\mathrm{CO}_{2}$ extraction, the extraction pressure was the very essential parameter. The solubility of supercritical liquid $\mathrm{CO}_{2}$ was improved as the pressure of liquid $\mathrm{CO}_{2}$ increasing. The reason was that as the press of critical $\mathrm{CO}_{2}$ increasing, not only the solubility of $\mathrm{CO}_{2}$ improved, but also the distance between particles of Chinese hickory kernel and solvent molecules were cut down. In this circumstance, efficient of extraction were increased and in favor of Chinese oil extraction. Furthermore, increasing reaction pressure also could decrease the reaction time and made the process safer and swift. As shown in Figure 5, at different extraction temperature of Chinese kernel oil were performed. When extraction pressure was less than $30 \mathrm{Mpa}$, the yields of Chinese hickory kernel oil increased, as the extraction pressure increasing. When extraction pressures were more than $30 \mathrm{Mpa}$, the yields of the kernel oil increased very slowly.

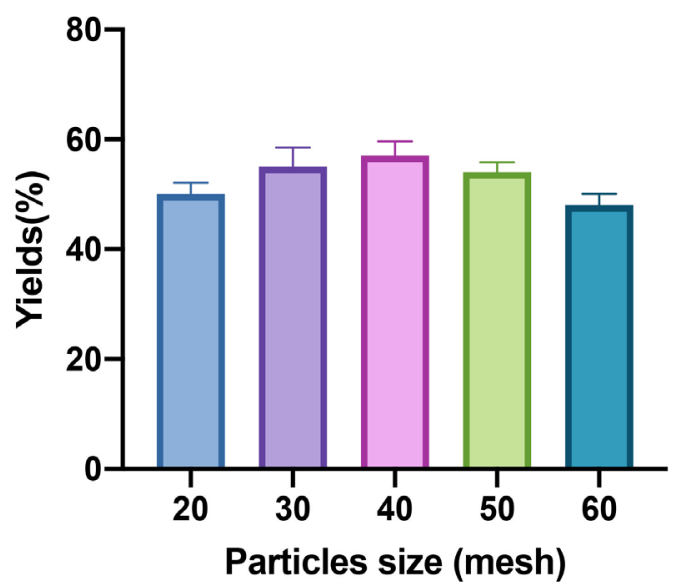

Figure 3. Effects of particles size. Data are presented as means, the error bars indicate standard deviations $(n=3)$. 


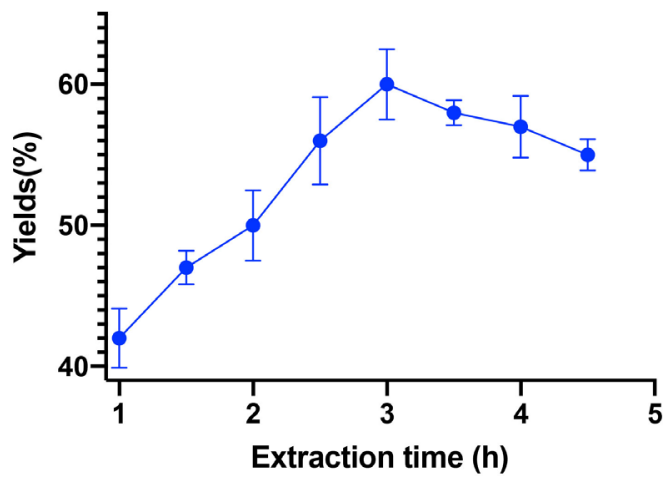

Figure 4. Effects of extraction time. Data are presented as means, the error bars indicate standard deviations $(n=3)$.

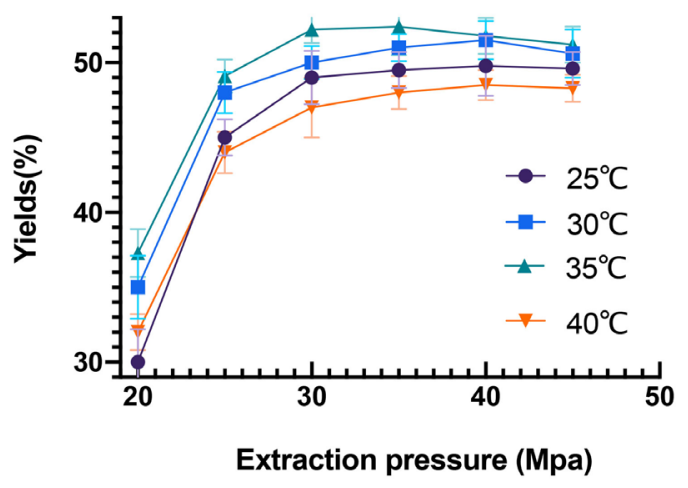

Figure 5. Effects of extraction pressure. Data are presented as means, the error bars indicate standard deviations $(n=3)$.

\subsection{Effects of Extraction Temperature}

Extraction temperature was an important factor for supercritical $\mathrm{CO}_{2}$ extraction. As reaction temperature raising, the heat refluxing becomes fierce, meanwhile the collide possibility between molecules of solvent and molecules in starting materials increased. Therefore, the solubility of liquid $\mathrm{CO}_{2}$ improved. However, as reaction temperature soaring, the density of liquid $\mathrm{CO}_{2}$ became lower, and the liquid $\mathrm{CO}_{2}$ carried less oil from Chinese hickory kernel oil. As shown in Figure 6 , in the experiments, below $40^{\circ} \mathrm{C}$, the yields of Chinese hickory kernel oil increased as the extraction temperature rising. However, above $40^{\circ} \mathrm{C}$, the yields of Chinese hickory kernel oil slightly decreased as the extraction temperature rising. Thus, $25^{\circ} \mathrm{C}$ to $35^{\circ} \mathrm{C}$ were optimum extraction temperature.

\subsection{Orthogonal Experiments Design}

Based on the single parameters experiment, four relevant factors were investigated: particles of Chinese hickory kernel, extraction time, extraction pressure, extraction temperature. The orthogonal table $\mathrm{L}_{9}(3)^{4}$ was designed as shown in Table 1. Three levels were set for each factor. According to pilot experiments, $35^{\circ} \mathrm{C}, 40^{\circ} \mathrm{C}$ and $45^{\circ} \mathrm{C}$ were selected as three levels for orthogonal experiments. And the extraction time selected $1.5 \mathrm{~h}, 2 \mathrm{~h}$ and $2.5 \mathrm{~h}$. From the pilot experimnets 


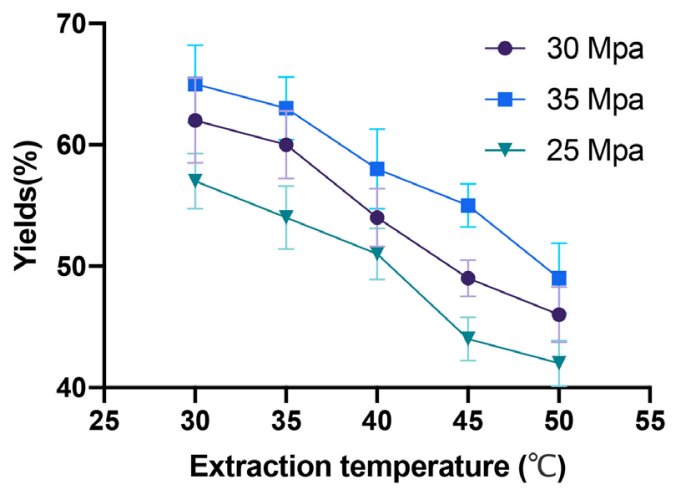

Figure 6. Effects of extraction temperature. Data is presented as means, the error bars indicate standard deviations $(n=3)$.

Table 2. Results of orthogonal experiments.

\begin{tabular}{cccccc}
\hline \multirow{2}{*}{ Trial No. } & \multicolumn{5}{c}{ Effective facotrs } \\
\cline { 2 - 5 } & A & B & C & D & \\
\hline 1 & 1 & 1 & 1 & 1 & 38.2 \\
2 & 1 & 2 & 2 & 2 & 60.4 \\
3 & 1 & 3 & 3 & 3 & 65.3 \\
4 & 2 & 1 & 2 & 3 & 63.2 \\
5 & 2 & 2 & 3 & 1 & 67.5 \\
6 & 2 & 3 & 1 & 2 & 67.8 \\
7 & 3 & 1 & 3 & 2 & 62.2 \\
8 & 3 & 2 & 1 & 3 & 61.8 \\
9 & 3 & 3 & 2 & 1 & 71.2 \\
K1 & 230.6 & 189.3 & 215.2 & 233.6 & \\
K2 & 257.8 & 253.3 & 261.3 & 248.7 & \\
K3 & 210.3 & 271.2 & 242.1 & 234.7 & \\
R & 33.21 & 76.1 & 43.2 & 21.2 & \\
\hline
\end{tabular}

Ki: the effect of each factor at level $i(i=1,2,3)$; R: range.

Table 3. Fatty acid profiles and contents of Chinese hickory kernel oil ${ }^{\star}$.

\begin{tabular}{cc}
\hline Fatty acids & Contents $^{* *}(100 \%)$ \\
\hline Palmitic acid & $4.7 \pm 0.07$ \\
palmitoleic acid & $0.13 \pm 0.04$ \\
stearic acid & $2.17 \pm 0.16$ \\
Oleic acid & $66.5 \pm 0.44$ \\
Linoleic acid & $24.1 \pm 0.35$ \\
Linolenic acid & $2.3 \pm 0.21$ \\
Arachidic acid & $0.12 \pm 0.02$ \\
Cis-11-eicosenoic acid & $0.24 \pm 0.12$ \\
Total saturated fatty acids & $6.92 \pm 0.21$ \\
Total unsaturated fatty acids & $93.05 \pm 0.12$ \\
\hline
\end{tabular}

${ }^{*}$ Each sample were performed 3 duplicates, and the value were demonstrated as mean \pm standard error: ${ }^{* *}$ The contents of the fatty acid based on the whole fatty acid in the Chinese hickory kernel. 
(see Figure 5) the extraction pressure was very important parameters for extraction, and the suitable pressure were $25 \mathrm{Mpa}, 30 \mathrm{Mpa}$ and $35 \mathrm{Mpa}$. According to the results of orthogonal experiments design (see Table 2), during the 4 factors of the experiments, Parameters of extraction time had the biggest range $(\mathrm{R}=$ 76.1) and extraction pressure, particles size and extraction temperature were as followed. These results showed that extraction time and extraction pressure had larger effects than extraction temperature and particle size. According to the tale of results orthogonal experiments design, the condition of $\mathrm{B}_{3} \mathrm{C}_{2} \mathrm{~A}_{2} \mathrm{D}_{2}$ was the optimum reaction parameters. At the optimum parameters, the yield of Chinese hickory kernel oil was 74.5\%.

\subsection{Fatty Acid Profiles}

Fatty acid profiles extracted from the optimum conditions, then the fatty acids were methylation to investigation on GC-MS, The result was shown in Table 3. Eight fatty acids were identified in Chinese hickory kernel oil. Unsaturated acids were predominant (total unsaturated fatty acids were 93.05\%). Among of them, Oleic acid was $66.5 \pm 0.44$ as the main components. Saturated fatty acids were $6.92 \pm 0.21$. This kind of fatty acid profiles is very similar with olive oil. Besides saturated and unsaturated oil, there are still have Linolenic acid, Arachidic acid and Cis-11-eicosenoic acid, and these fatty acids also very good for human health [20].

\section{Conclusion}

In this research, the different extraction methods were explored and supercritical $\mathrm{CO}_{2}$ selected as green and non-toxic solvent to extract Chinese kernel oil. Four experiment factors were selected to carry out the single factor reaction. Through single factor reaction, four levels are selected respectively. According to the results orthogonal experiments design, the condition of $\mathrm{B}_{3} \mathrm{C}_{2} \mathrm{~A}_{2} \mathrm{D}_{2}$ was the optimum reaction parameters. When the experiments were carried out at the optimum parameters, the yield of Chinese hickory kernel oil was $74.5 \%$. The oil fatty acids profile were analyzed, the results showed that total unsaturated fatty acids were $93.05 \%$. Among them, oleic acid was $66.5 \pm 0.44$ as the main component. Saturated fatty acids were $6.92 \pm 0.21$.

\section{Acknowledgements}

The authors gratefully acknowledge Wenbing Chen for providing us lab assistance. This work was supported by National Key R\&D Program of Zhejiang Province (2018C2006) and the cooperation project of Zhejiang Province and CAF (2017B04)

\section{Conflicts of Interest}

The authors declare no conflicts of interest regarding the publication of this paper. 


\section{References}

[1] Amarni, F. and Kadi, H. (2010) Kinetics Study of Microwave-Assisted Solvent Extraction of Oil from Olive Cake Using Hexane: Comparison with the Conventional Extraction. Innovative Food Science Emerging Technologies, 11, 322-327. http://www.sciencedirect.com/science/article/pii/S1466856410000044 https://doi.org/10.1016/j.ifset.2010.01.002

[2] Rico, C., Rico, J.L. and Lasa, C. (2012) Anaerobic Digestion of the Liquid Fraction of Dairy Manure Separated by Screw Pressing and Centrifugation. Biosystems Engineering, 112, 344-351. https://doi.org/10.1016/j.biosystemseng.2012.05.006

[3] Yilmaz, E., Guneser, B.A. and Ok, S. (2018) Valorization of Grapefruit Seeds: Cold Press Oil Production. Waste and Biomass Valorization, 10, 2713-2724. https://doi.org/10.1007/s12649-018-0286-x

[4] Brunner, G. (2005) Supercritical Fluids: Technology and Application to Food Processing. Journal of Food Engineering, 67, 21-33. http://www.sciencedirect.com/science/article/pii/S0260877404003383 https://doi.org/10.1016/j.jfoodeng.2004.05.060

[5] Carmen, W.H. (2002) A Review of Modern Sample-Preparation Techniques for the Extraction and Analysis of Medicinal Plants. Analytical and Bioanalytical Chemistry, 373, 23-30. https://doi.org/10.1007/s00216-002-1265-3

[6] Ibáñez, E., Mendiola, J.A. and Castro-Puyana, M. (2016) Supercritical Fluid Extraction. In: Caballero, B., Finglas, P.M. and Toldrá, F., Eds., Encyclopedia of Food and Health, Academic Press, Oxford, 227-233.

http://www.sciencedirect.com/science/article/pii/B9780123849472006759 https://doi.org/10.1016/B978-0-12-384947-2.00675-9

[7] Mendes, R.L., Nobre, B.P., Cardoso, M.T., Pereira, A.P. and Palavra, A.F. (2003) Supercritical Carbon Dioxide Extraction of Compounds with Pharmaceutical Importance from Microalgae. Inorganica Chimica Acta, 356, 28-334.

http://www.sciencedirect.com/science/article/pii/S0020169303003633 https://doi.org/10.1016/S0020-1693(03)00363-3

[8] Mukhopadhyay, M. (2000) Natural Extracts Using Supercritical Carbon Dioxide. CRC Press, London. https://doi.org/10.1201/9781420041699

[9] Grosso, C., Ferraro, V., Figueiredo, A.C., Barroso, J.G., Coelho, J.A. and Palavra, A.M. (2008) Supercritical Carbon Dioxide Extraction of Volatile Oil from Italian Coriander Seeds. Food Chemistry, 111, 197-203.

http://www.sciencedirect.com/science/article/pii/S0308814608003312 https://doi.org/10.1016/j.foodchem.2008.03.031

[10] Yuan, H., Zhao, L., Chen, J.J., Yang, Y., Xu, D., Tao, S.C., Zheng, S., Shen, Y.R., He, Y., Shen, C., et al. (2018) Identification and Expression Profiling of the Aux/IAA Gene Family in Chinese Hickory (Carya Cathayensis Sarg.) during the Grafting Process. Plant Physiology and Biochemistry, 127, 55-63.

https://doi.org/10.1016/j.plaphy.2018.03.010

[11] Fukuda, T., Ito, H. and Yoshida, T. (2003) Antioxidative Polyphenols from Walnuts (Juglans Regia L.). Phytochemistry, 63, 795-801. http://www.sciencedirect.com/science/article/pii/S0031942203003339 https://doi.org/10.1016/S0031-9422(03)00333-9

[12] Savage, G.P. (2001) Chemical Composition of Walnuts (Juglans Regia L.) Grown in New Zealand. Plant Foods for Human Nutrition, 56, 75-82. https://doi.org/10.1023/A:1008175606698

[13] Huang, Y.-J., Zhou, Q., Huang, J.-Q., Zeng, Y.-R., Wang, Z.-J., Zhang, Q.-X., Zhu, 
Y.-H., Shen, C. and Zheng, B.-S. (2015) Transcriptional Profiling by DDRT-PCR Analysis Reveals Gene Expression during Seed Development in Carya cathayensis Sarg. Plant Physiology and Biochemistry, 91, 28-35.

http://www.sciencedirect.com/science/article/pii/S0981942815000704 https://doi.org/10.1016/j.plaphy.2015.03.008

[14] Stark, C., Mcneil, D. and Savage, G. (2000) The Effect of Storage Conditions on the Stability of Peroxide Values of New Zealand Grown Walnuts. Proceedings of the Nutrition Society of New Zealand, 25, 1-12.

[15] Chen, F., Zhang, Q., Fei, S., Gu, H. and Yang, L. (2017) Optimization of Ultrasonic Circulating Extraction of Samara Oil from Acer Saccharum Using Combination of Plackett-Burman Design and Box-Behnken Design. Ultrasonics Sonochemistry, 35, 161-175. https://doi.org/10.1016/j.ultsonch.2016.09.015

[16] Benito-Román, O., Rodríguez-Perrino, M., Teresa Sanz, M., Melgosa, R. and Beltrán, S. (2018) Supercritical Carbon Dioxide Extraction of Quinoa Oil: Study of the Influence of Process Parameters on the Extraction Yield and Oil Quality. The Journal of Supercritical Fluids, 139, 62-71. https://doi.org/10.1016/j.supflu.2018.05.009

[17] Li, H.-Z., Zhang, Z.-J., Hou, T.-Y., Li, X.-J. and Chen, T. (2015) Optimization of Ultrasound-Assisted Hexane Extraction of Perilla Oil Using Response Surface Methodology. Industrial Crops and Products, 76, 18-24.

http://www.sciencedirect.com/science/article/pii/S0926669015301898 https://doi.org/10.1016/j.indcrop.2015.06.021

[18] Sharif, K.M., Rahman, M.M., Azmir, J., Mohamed, A., Jahurul, M.H.A., Sahena, F. and Zaidul, I.S.M. (2014) Experimental Design of Supercritical Fluid Extraction-A Review. Journal of Food Engineering, 124, 105-116.

http://www.sciencedirect.com/science/article/pii/S0260877413005128 https://doi.org/10.1016/j.jfoodeng.2013.10.003

[19] Guo, L., Xie, M.-Y., Yan, A.-P., Wan, Y.-Q. and Wu, Y.-M. (2006) Simultaneous Determination of Five Synthetic Antioxidants in Edible Vegetable Oil by GC-MS. Analytical and Bioanalytical Chemistry, 386, 1881-1887.

https://doi.org/10.1007/s00216-006-0738-1

[20] Hu, L.S., Du, M.H. and Zhang, J.P. (2018) Physicochemical Properties and Nutritional Ingredients of Kernel Oil of Carya cathayensis Sarg. American Journal of Plant Sciences, 9, 2494-2503. https://doi.org/10.4236/ajps.2018.912180 